\title{
Treatment of advanced basal cell carcinoma with sonidegib: perspective from the 30-month update of the BOLT trial
}

\author{
Leon Chen ${ }^{1}$, Alexander B Aria ${ }^{2}$, Sirunya Silapunt ${ }^{1}$, Heng-Huan Lee ${ }^{3}$ \& Michael R Migden*,4 \\ ${ }^{1}$ Department of Dermatology, The University of Texas McGovern Medical School at Houston, Houston, TX 77030, USA \\ ${ }^{2}$ The University of Texas McGovern Medical School at Houston, Houston, TX 77030, USA \\ ${ }^{3}$ Department of Molecular \& Cellular Oncology, The University of Texas MD Anderson Cancer Center, Houston, TX 77030 USA \\ ${ }^{4}$ Departments of Dermatology \& Head \& Neck Surgery, The University of Texas MD Anderson Cancer Center, Houston, TX, USA \\ * Author for correspondence: Tel.: +1 713563 1665; Fax: +1 713745 3597; mrmigden@mdanderson.org
}

Sonidegib, a hedgehog pathway inhibitor, was approved by the US FDA for the treatment of locally advanced basal cell carcinoma which cannot be readily treated with surgery or radiotherapy. The pharmacology and pharmacokinetics of sonidegib will be discussed in this review. Additionally, an in-depth analysis of the BOLT trial and data from the 30-month update will be included. This will serve as an update to a previously published article which reported the 12-month update of the BOLT trial.

First draft submitted: 9 September 2017; Accepted for publication: 23 October 2017; Published online: 9 November 2017

Keywords: basal cell carcinoma • BOLT • hedgehog pathway inhibitor • HPI • laBCC • locally advanced basal cell carcinoma $\bullet \mathrm{mBCC} \bullet$ metastatic basal cell carcinoma • sonidegib

\section{Background}

Basal cell carcinoma (BCC) is the most common skin cancer in humans. Annually, there are 2.8 million cases that result in approximately 3000 deaths [1]. The use of surgical excision for the treatment of BCC results in a 5-year cure rate close to $90 \%[2,3]$. The 5 -year recurrence rate decreases to $0.7-2.4 \%$ when Mohs micrographic surgery (MMS) is performed [4-7]. Alternative nonsurgical approaches include cryotherapy, electrodesiccation and curettage, photodynamic therapy, radiation, or topical agents such as imiquimod or 5-fluorouracil. These options usually confer a lower cure rate and lack confirmation of tumor clearance on histology. Although metastasis of BCC has a very low incidence of $0.0028-0.55 \%$, BCCs that fail surgery and/or radiation can become locally advanced $[8,9]$. The potential disfigurement and/or morbidity associated with further surgery warrants consideration of an alternative treatment modality [10].

Abnormalities in the hedgehog signaling pathway and PTCH1 and SMO mutations are implicated in the pathogenesis of basal cell carcinoma [11]. Approximately 95\% of patients with sporadic BCCs have mutations in this pathway [11-13]. Sonidegib has been approved in the USA, EU, Switzerland and Australia for the treatment of locally advanced BCC (laBCC) that is either recurrent or not amenable to surgery or radiation. Additionally, sonidegib is also approved in Switzerland and Australia for metastatic BCC (mBCC). Another hedgehog pathway inhibitor (HPI), vismodegib, was approved for laBCC and $\mathrm{mBCC}$ in the USA, EU, Switzerland, Australia and other countries.

The BOLT trial was a multicenter Phase II randomized, double-blinded clinical trial studying the use of two different doses of sonidegib for the treatment of laBCC or mBCC [14]. The US FDA's approval of sonidegib was based on a significant objective response rate (ORR) achieved in this trial. In this review, sonidegib and the BOLT trial will be discussed in detail [14,15]. The data from the 30-month update will also be provided and compared with the original data from primary analysis [16].

\section{Introduction to the compound}

Sonidegib under the trade name Odomzo (Sun Pharmaceutical Industries Ltd, Mumbai, India) was approved by the FDA in July 2015 for patients 18 years or older with BCCs that either recurred or were not amenable to

Future 8 Medicine 


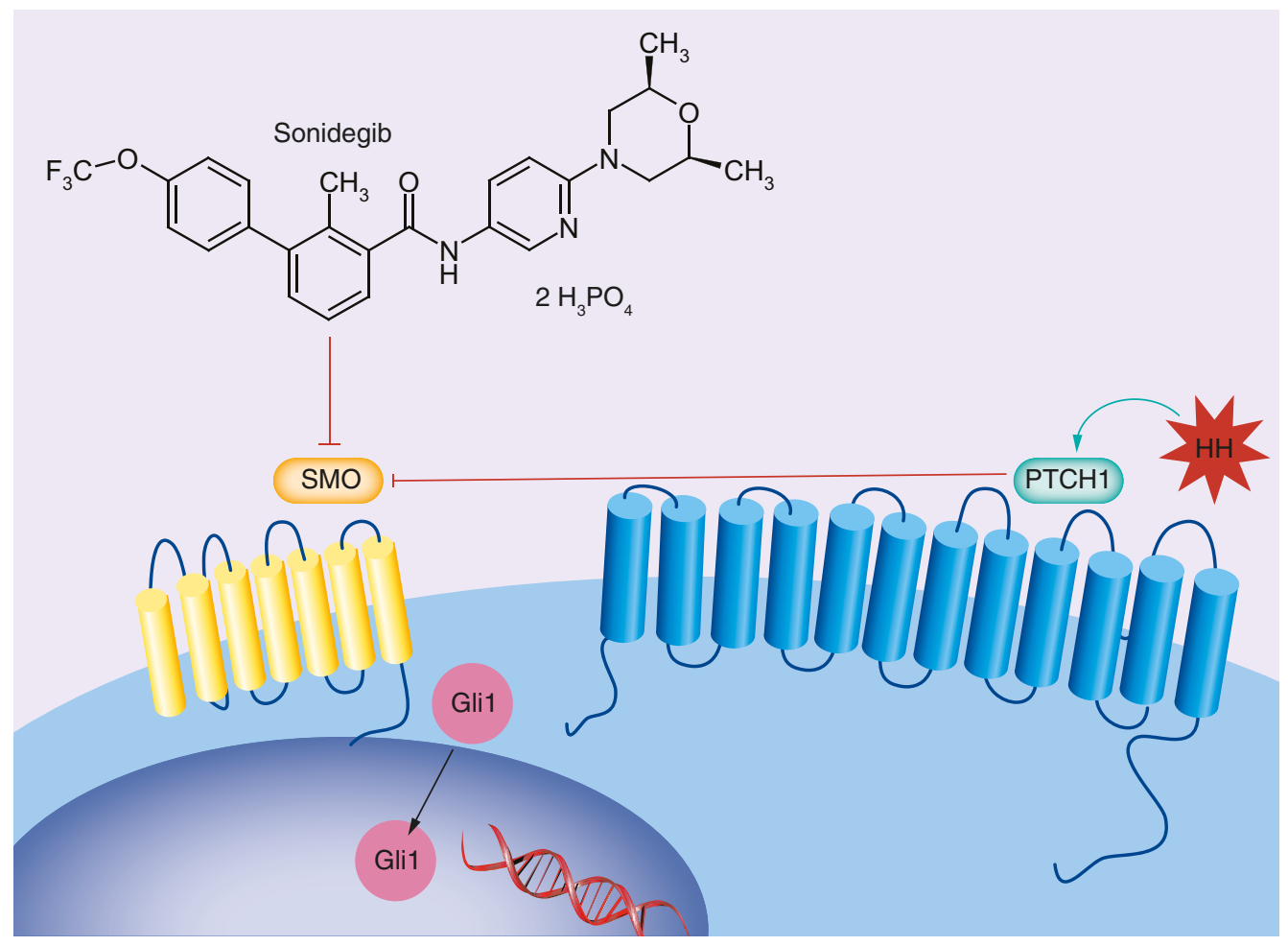

Figure 1. Action of sonidegib on the hedgehog signaling pathway. When hedgehog signaling ligand is present and bind to the 12 transmembrane protein PTCH1, the seven membrane spanning receptor SMO is no longer inhibited via PTCH1-mediated inhibition and allows transcription factor Gli1 to enter the cell nucleus, stimulating cell division and tumorigenesis. Sonidegib inhibits the hedgehog pathway via SMO antagonism.

HH: Hedgehog.

Reproduced with permission from [15].

surgery or radiation therapy. The European Commission approved sonidegib for the same indication in August 2015. Because hedgehog pathway signaling plays a crucial role in embryogenesis, sonidegib is contraindicated in women who are pregnant or breast-feeding as it may lead to severe birth defects or fetal demise.

During embryogenesis, the hedgehog pathway is activated and promotes the normal development of embryonic cells. However, this pathway typically remains quiescent in normal adult tissues through the suppression of the seven-pass transmembrane receptor SMO by a transmembrane protein PTCH1 on the surface of cells $[12,17]$. The hedgehog signaling ligand activates the pathway when it binds to PTCH1, leading to disinhibition of SMO. This allows the transcription factor Gli to enter the cell nucleus and promote cell division and tumorigenesis (Figure 1) [18].

Sonidegib, also known as LDE225, was discovered in 2010. Its chemical structure is N-(6-((2 S, $6 \mathrm{R})-2$, 6dimethylmorpho-lino) pyridine-3-yl)-2-methyl-40-(trifluoromethoxy) biphenyl-3-carboxamide and it has an $\mathrm{IC}_{50}$ of $11 \mathrm{nM}$ in humans [19]. In preclinical studies, sonidegib was found to have a high oral bioavailability, high tissue penetration, and the ability to cross the blood-brain barrier. Patients with advanced solid tumors tolerated a maximum dose of $800 \mathrm{mg}$ daily and $250 \mathrm{mg}$ twice a day in a Phase I study with doses ranging between 100 and $3000 \mathrm{mg}$ daily and 250 and $850 \mathrm{mg}$ twice daily. No clinical advantage was seen with twice-daily dosing; accordingly, once-daily dosing is the current recommendation for ongoing sonidegib trials. Muscle spasms were the most commonly reported adverse event in the Phase I trial. Elevated serum creatine kinase without evidence of cardiac muscle injury was the primary dose-limiting toxicity and was reported in $18 \%$ of patients. The investigators were unable to establish a relationship between muscle cramps and elevated creatine kinase, as many patients experienced muscle cramps with normal serum levels of creatine kinase while others had no muscle cramps and elevated levels of creatine kinase [20]. Sonidegib's high binding capacity to serum proteins may explain its relatively long half-life (29.6 days) [21]. Sonidegib has a maximum serum concentration $\left(\mathrm{C}_{\max }\right)$ of $1030 \mathrm{ng} / \mathrm{ml}$ with a time to achieve this concentration $\left(t_{\max }\right)$ of $2-4 \mathrm{~h}$. Sonidegib reaches steady state roughly 4 months after an initial dose and 
has a volume of distribution of around $2500 \mathrm{~L}$. CYP3A is the main enzyme responsible for metabolizing sonidegib and drug interactions with this hepatic enzyme can potentially increase the risk for muscle spasms. Unabsorbed sonidegib is excreted in the feces. Once sonidegib is absorbed, it is eliminated chiefly through hydrolytic and oxidative metabolism. Absorbed sonidegib was found to be excreted in the feces (70\%) and urine (30\%) [22].

In 2011, a randomized, double-bind, vehicle-controlled study was conducted on the use of $0.75 \%$ sonidegib topical cream two-times per day for 4 weeks for the treatment of 27 total BCCs among eight nevoid BCC syndrome patients [23]. Topical cream use on 13 BCCs achieved a complete response in three BCCs, a partial response in nine, and failure of response in one. A mean volume reduction of $56 \%$ was found in these BCC on day 29 . Vehicle control use on 14 BCCs achieved a partial response in only one BCC and no response in the other 13. The success of this trial was unable to be reproduced in other topical sonidegib trials of larger sample size, likely as a result of limited cutaneous penetration of the drug in topical formulation [24]. In addition to BCC, clinical trials on the use of sonidegib for leukemia, myelofibrosis and solid tumors such as medulloblastoma are underway. Vismodegib is another hedgehog pathway inhibitor which was proven to be efficacious in the ERIVANCE trial. It has a side effect profile similar to that of sonidegib. Vismodegib was approved in January 2012 by the FDA for the treatment of recurrent laBCC after surgery, laBCC not amenable to surgery or radiation therapy, and mBCC.

\section{Overview of the BOLT trial}

The BOLT trial is a randomized, double-blind, multicenter, Phase II study conducted in 58 centers in 12 countries. This study investigated the use of sonidegib for histologically confirmed laBCC not amenable to surgery or radiation therapy or refractory $\mathrm{mBCC}$ [14]. Patients 18 years or older were randomized into two treatment arms of $200 \mathrm{mg}$ (dose with lowest efficacy) and $800 \mathrm{mg}$ (maximum tolerated daily dose) sonidegib once daily in a 1:2 ratio, respectively [14]. Dose reductions or discontinuations were implemented when patients developed symptoms indicative of possible toxicity. The investigators and central review committee assessed mBCC tumors based on Response Criteria in Solid Tumors (RECIST) version 1.1 and assessed laBCC based on modified RECIST as the use of RECIST version 1.1 alone cannot assess tumors adequately in the setting of scarring, ulceration or fibrosis [25].

The proportion of patients with laBCC or mBCC who achieved an ORR was the primary end point of the BOLT trial. Both complete response (CR) and partial response (PR) were included in the ORR. CR was achieved in a patient when all lesions had resolved, and study's independent review panel determined surveying biopsies from two or more sites were negative. PR was defined by a $50 \%$ or greater decrease in the sum of the products of perpendicular diameter (WHO criteria) based on photographs of lesions as well as a minimum $30 \%$ reduction in the sum of diameters of all target lesions by MRI (RECIST).

A total of 230 patients were enrolled in the study. To achieve a 1:2 ratio between treatment groups, 79 patients (66 with laBCC and 13 with $\mathrm{mBCC}$ ) were randomized to receive $200 \mathrm{mg}$ of sonidegib and 151 patients (128 with laBCC and 23 with $\mathrm{mBCC}$ ) were randomized to receive $800 \mathrm{mg}$. Both treatment arms successfully met the primary end point of ORR as assessed by central review at the time of primary analysis (cutoff of 28 June 2013). An objective response was achieved by 20 of 55 patients (36\%; 95\% CI: 24-50) in the $200 \mathrm{mg}$ treatment group and 39 of 116 patients (34\%; 95\% CI: 25-43) in the $800 \mathrm{mg}$ treatment group as assessed by central review. No substantial difference in ORR could be found in different subgroups stratified by geographic location or histologic subtype. The proportion of patients achieving a CR, elapsed time to tumor response, duration of tumor response, duration progression-free survival, and patient safety were the secondary end points evaluated in the study. Exploratory analysis of the change in transcriptional factor Gli1 expression was conducted on tumor biopsy samples collected at screening week 9, week 17 and the completion of treatment. A reduction in Glil expression as a marker of hedgehog pathway inhibition was expected and confirmed in patients with a CR, PR or stable disease. Although a similar efficacy profile was shown for both the 200 and $800 \mathrm{mg}$ treatment arms, the $200 \mathrm{mg}$ treatment arm had a lower rate of adverse events, longer duration of treatment, and a lower discontinuation rate, thus demonstrating a favorable benefit-to-risk profile.

\section{Safety \& tolerability}

Alopecia, muscle spasms, nausea, dysgeusia (disturbance of taste), nausea, fatigue and elevated blood creatine kinase were the most frequently reported adverse events in the BOLT trial [14]. At the time of primary data analysis, three of 79 patients in the $200 \mathrm{mg}$ sonidegib group and 13 of 150 patients in the $800 \mathrm{mg}$ group discontinued sonidegib treatment as a result of muscle spasms. The most commonly reported grade 3-4 adverse event was elevated creatine kinase concentration. 14\% of patients in the $200 \mathrm{mg}$ group and $30 \%$ in the $800 \mathrm{mg}$ group developed serious adverse 
events, of which rhabdomyolysis was the most frequently reported. Of note, these reported cases of rhabdomyolysis failed to meet the criteria of a tenfold increase in serum creatine kinase concentration from upper limit of normal and a 1.5-fold increase in serum creatinine concentration from baseline as defined by an independent safety review committee comprised of experts on muscle toxicity.

Dysgeusia, a well-documented side effect of HPI use, was reported by $38 \%$ of patients who received $200 \mathrm{mg}$ sonidegib daily and 59\% of patients who received $800 \mathrm{mg}$ sonidegib daily [14]. In the ERIVANCE trial, greater than $50 \%$ of patients who took vismodegib complained of dysgeusia, leading some to discontinue their therapy [26]. A study in which mice were given LDE225 for up to 28 days showed that disruption of the hedgehog signaling pathway interfered with taste buds and chorda tympani nerve response to taste bud stimulation [27].

Because BCC may have a negative effect on patients' quality of life (QoL), the effect of sonidegib therapy on QoL was studied in the BOLT with questionnaires completed at different stages of treatment. The questionnaires used $(n=2)$ were developed by the European Organization for Research and Treatment of Cancer (EORTC), and include the relevant predetermined subscales of Quality of Life Questionnaire C30 (QLQ-C30) for the assessment of QoL for cancer patients and the Head and Neck Cancer Module 35 (QLQ-H\&N35) for head and neck cancer specifically. The QLQ-C30 has 15 subscales with 30 items which allow patients to communicate the symptoms of their disease and any possible undesirable treatment side effects. For the BOLT trial, four subscales with 12 items, which were most pertinent to patients with advanced BCC, were selected for analysis. Likewise, although the QLQ-H\&N35 has 18 subscales with 35 items, only three subscales with ten items were deemed relevant for these patients selected for analysis in the BOLT trial. In the primary data, the majority of laBCC patients who responded to the QLQ-C30 and H\&N35 questionnaires had maintenance of or improvement in their scores with a somewhat greater percentage of patients in the $800 \mathrm{mg}$ group reporting a decline of QoL indicators. Most $\mathrm{mBCC}$ patients who responded to the questionnaires had maintenance of or improvement in their scores on both questionnaires. The findings show that sonidegib has demonstrable tolerability and can maintain or improve the self-reported QoL of most patients with laBCC or mBCC.

\section{0-month follow-up}

The initial BOLT trial manuscript collected data for up to 6 months after the last patient was randomized with a median follow-up of 13.9 months and a cutoff date of 28 June 2013 [14]. The 12-month update cutoff date was 31 December 2013. This section will detail the safety and efficacy data collected 30 months after the randomization of the last patient with a cutoff date of 10 July 2015. Sonidegib treatment was continued for each patient until he or she had progression of disease, intolerable toxicity, death or another reason for discontinuation of the drug. A total of 144 patients $(63 \%)$ had discontinued sonidegib therapy at the time of primary analysis primarily as a result of adverse side effects [14]. At the 12- and 30-month follow-ups, 77.8 and $93.0 \%$ of patients had stopped treatment, respectively [28].

For laBCC, a comparison of the 30-month data to the 12-month data showed similar ORRs for the $200 \mathrm{mg}$ group ( 56.1 vs $57.6 \%$, respectively) and the $800 \mathrm{mg}$ group of ( 45.3 vs $43.8 \%$, respectively) per central review (Table 1). Clinical benefit, defined as the percentage of patients who had a reduction as their maximal change in tumor size from baseline, remained unchanged between the 12- and 30-month updates per central review, and was observed in $92.3 \%$ of patients (48/52) treated with sonidegib $200 \mathrm{mg}$ and $90.1 \%$ of patients $(91 / 101)$ treated with sonidegib $800 \mathrm{mg}$. The disease control rate (complete response + partial response + stable disease) for the $200 \mathrm{mg}$ arm remained at $90.8 \%$ at 30 months and increased from $81.3 \%$ at 12 months to $82.8 \%$ at 30 months for the $800 \mathrm{mg}$ arm. The percentage of patients achieving a complete or partial response can be seen in Figure 2 . Additionally, at 30 months the median duration of response (DOR) increased for both the 200 and $800 \mathrm{mg}$ groups to 26.1 versus 20.2 months in the 12 -month update and 23.7 versus 19.8 months in the 12 -month update, respectively. Per central review, the median durations of progression-free survival (PFS) was 22.1 months in the $200-\mathrm{mg}$ arm and 22.0 months in the $800-\mathrm{mg}$ arm. Five laBCC patients in the $200 \mathrm{mg}$ arm and $11 \mathrm{laBCC}$ patients in the $800 \mathrm{mg}$ arm had died by the 30 -month update.

For mBCC, the ORRs for the 200 and $800 \mathrm{mg}$ arms remained unchanged for the 30 -month data in comparison to the 12-month data per central review and were 7.7 and $17.4 \%$, respectively. Clinical benefit as previously defined remained the same at 30 months in comparison to 12 months, and was observed in 91.7 and $84.2 \%$ of patients in the 200 and $800 \mathrm{mg}$ arms, respectively. Additionally, disease control rate remained unchanged between 30 and 12 months at a value of $92.3 \%$ for the $200 \mathrm{mg}$ arm and $91.3 \%$ for the $800 \mathrm{mg}$ arm per central review. Per central review at 30 months, the estimated median DOR for the $200 \mathrm{mg}$ arm was 24.0 months; for the $800 \mathrm{mg}$ arm, the 
Table 1. The response rates for 200 and $800 \mathrm{mg}$ sonidegib groups from primary analysis, the 12-month update, and the 30-month update of BOLT trial.

\begin{tabular}{|c|c|c|c|c|c|c|c|c|c|c|c|c|}
\hline & \multicolumn{4}{|c|}{ Primary analysis (28 June 2013 , data cutoff) } & \multicolumn{4}{|c|}{$\begin{array}{l}\text { 12-month update (31 December 2013, data } \\
\text { cutoff) }\end{array}$} & \multicolumn{4}{|c|}{ 30-month update (10 July 2015 , data cutoff) } \\
\hline & \multicolumn{2}{|c|}{$200 \mathrm{mg}$ sonidegib } & \multicolumn{2}{|c|}{$800 \mathrm{mg}$ sonidegib } & \multicolumn{2}{|c|}{$200 \mathrm{mg}$ sonidegib } & \multicolumn{2}{|c|}{$800 \mathrm{mg}$ sonidegib } & \multicolumn{2}{|c|}{$200 \mathrm{mg}$ sonidegib } & \multicolumn{2}{|c|}{$800 \mathrm{mg}$ sonidegib } \\
\hline & $\begin{array}{l}\text { laBCC } \\
(n=66)\end{array}$ & $\begin{array}{l}m B C C \\
(n=13)\end{array}$ & $\begin{array}{l}\text { laBCC } \\
(n=128)\end{array}$ & $\begin{array}{l}m B C C \\
(n=23)\end{array}$ & $\begin{array}{l}\text { laBCC } \\
(n=66)\end{array}$ & $\begin{array}{l}m B C C \\
(n=13)\end{array}$ & $\begin{array}{l}\text { laBCC } \\
(n=128)\end{array}$ & $\begin{array}{l}m B C C \\
(n=23)\end{array}$ & $\begin{array}{l}\text { laBCC } \\
(n=66)\end{array}$ & $\begin{array}{l}m B C C \\
(n=13)\end{array}$ & $\begin{array}{l}\text { laBCC } \\
(n=128)\end{array}$ & $\begin{array}{l}m B C C \\
(n=23)\end{array}$ \\
\hline $\begin{array}{l}\text { Proportion } \\
\text { of patients } \\
\text { with } \\
\text { objective } \\
\text { response } \\
\text { (central } \\
\text { review; \%) }\end{array}$ & 47 & 15 & 35 & 17 & 58 & 8 & 44 & 17 & 56 & 8 & 45 & 17 \\
\hline $\begin{array}{l}\text { Complete } \\
\text { response } \\
(\%)\end{array}$ & 3 & 0 & 0 & 0 & 5 & 0 & 2 & 0 & 5 & 0 & 2 & 0 \\
\hline $\begin{array}{l}\text { Partial } \\
\text { response } \\
(\%)\end{array}$ & 44 & 15 & 35 & 17 & 53 & 8 & 42 & 17 & 52 & 8 & 44 & 17 \\
\hline $\begin{array}{l}\text { Disease } \\
\text { control } \\
(\%)\end{array}$ & 91 & 92 & 78 & 83 & 91 & 92 & 82 & 91 & 91 & 92 & 82 & 91 \\
\hline
\end{tabular}

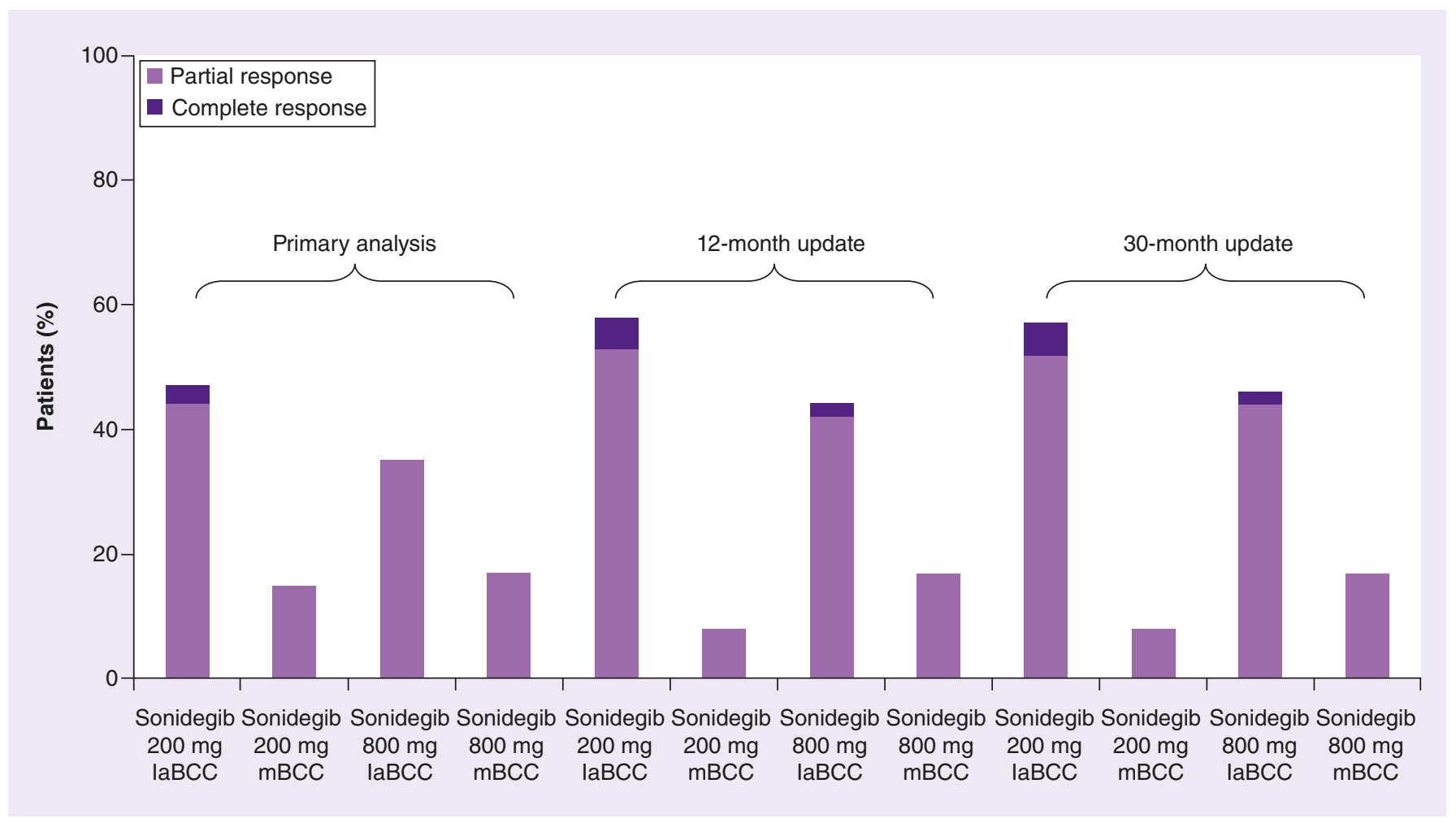

Figure 2. Proportion of patients with objective response during primary analysis, 12-month update and 30-month update. laBCC: Locally advanced BCC; mBCC: Metastatic basal cell carcinoma.

Data taken from [14-16].

median DOR was not reached due to the proportion of patients continuing to respond to treatment in this group at the time of data cutoff. Per central review, the median durations of PFS was 13.1 months in the 200-mg arm and 11.1 months in the $800-\mathrm{mg}$ arm. At the time of the 30-month analysis, 11 patients with mBCC had died. 
Table 2. The most common adverse events reported in primary analysis, 12-month update, and 30-month update of BOLT Trial.

\begin{tabular}{|c|c|c|c|c|c|c|}
\hline \multirow[t]{2}{*}{ Adverse event } & \multicolumn{2}{|c|}{ Primary analysis (28 June 2013 , data cutoff) } & \multicolumn{2}{|c|}{$\begin{array}{l}\text { 12-month update (31 December 2013, data } \\
\text { cutoff) }\end{array}$} & \multicolumn{2}{|c|}{ 30-month update (10 July 2015 , data cutoff) } \\
\hline & $\begin{array}{l}200 \text { mg sonidegib } \\
(n=79) ; \text { all } / \text { grade } 3 \\
\text { or } 4\end{array}$ & $\begin{array}{l}800 \mathrm{mg} \text { sonidegib } \\
(n=150) ; \text { all } / \text { grade } 3 \\
\text { or } 4\end{array}$ & $\begin{array}{l}200 \text { mg sonidegib } \\
(n=79) ; \text { all } / \text { grade } 3 \\
\text { or } 4\end{array}$ & $\begin{array}{l}800 \mathrm{mg} \text { sonidegib } \\
(n=150) ; \text { all } / \text { grade } 3 \\
\text { or } 4\end{array}$ & $\begin{array}{l}200 \mathrm{mg} \text { sonidegib } \\
(\mathrm{n}=79) ; \text { all } / \text { grade } 3 \\
\text { or } 4\end{array}$ & $\begin{array}{l}800 \mathrm{mg} \text { sonidegib } \\
(n=150) ; \text { all } / \text { grade } 3 \text { or } \\
4\end{array}$ \\
\hline Muscle spasm (\%) & $49 / 3$ & $100 / 5$ & $52 / 3$ & $69 / 5$ & $55 / 3$ & $69 / 5$ \\
\hline Alopecia (\%) & $43 / 1$ & $55 / \mathrm{NA}$ & $49 / N A$ & 57/NA & $50 / 0$ & $58 / 0$ \\
\hline Dysgeusia (\%) & $38 / 0$ & $59 /<1$ & $41 / N A$ & $60 / \mathrm{NA}$ & $45 / 0$ & $60 / 0$ \\
\hline Nausea (\%) & $33 / 1$ & $45 / 3$ & $35 / 1$ & $47 / 3$ & $39 / 1$ & $47 / 3$ \\
\hline $\begin{array}{l}\text { Blood creatine kinase } \\
\text { increased }(\%)\end{array}$ & $29 / 7$ & $37 / 12$ & $30 / 6$ & $37 / 15$ & $31 / 7$ & $37 / 13$ \\
\hline Fatigue (\%) & $29 / 0$ & $36 / 2$ & $29 / 0$ & $36 / 2$ & $30 / 1$ & $37 / 2$ \\
\hline Weight decreased (\%) & $27 / 1$ & $38 / 5$ & $29 / 3$ & $42 / 6$ & $30 / 5$ & $43 / 6$ \\
\hline Diarrhea (\%) & $24 / 0$ & $22 / 0$ & $30 / 1$ & $23 / 0$ & $32 / 1$ & $24 / 0$ \\
\hline
\end{tabular}

At the 30-month analysis, the safety profile of sonidegib appeared similar to that seen at primary analysis and the 12-month update. At 30 months, the median duration of exposure was 11.0 months for the $200 \mathrm{mg}$ group and 6.6 months for the $800 \mathrm{mg}$ group. The most commonly reported adverse effects were muscle spasms, dysgeusia, nausea, alopecia, weight loss, increased creatine kinase, fatigue, decreased appetite, myalgia and vomiting which were less common in the $200 \mathrm{mg}$ group than the $800 \mathrm{mg}$ group and similarly reported for both laBCC and mBCC patients (Table 2). Also at 30 months, 43.0 and $66.7 \%$ of patients in the 200 and $800 \mathrm{mg}$ groups had adverse events that required dose interruption and/or reductions. Additionally, 30.4 and $40 \%$ of patients in the 200 and $800 \mathrm{mg}$ groups had adverse events that lead to treatment discontinuation. Serious adverse events regardless of cause occurred in 20.3 and $38.7 \%$ of patients taking 200 and $800 \mathrm{mg}$ of sonidegib, respectively. Treatment-related serious adverse events were reported for 3.8 and $16.0 \%$ of patients in the 200 and $800 \mathrm{mg}$ groups, respectively. The most commonly reported serious adverse events were increased creatine kinase (1.3\% for each group) and rhabdomyolysis (3.3\% for each group). Because none of the patients progressed to renal impairment, the cases of rhabdomyolysis were not officially confirmed by an independent review and adjudication committee of muscle toxicity experts [14]. A total of eight patients died while receiving treatment including four with laBCC (one patient in the $200 \mathrm{mg}$ group, three in the $800 \mathrm{mg}$ group) and four with $\mathrm{mBCC}$ (four patients in the $800 \mathrm{mg}$ group). None of the deaths were thought to be related to treatment. During the primary analysis, four deaths occurred including two with $\mathrm{mBCC}$ due to progressive disease and two with laBCC due to cardiac conditions. Following the primary analysis, four deaths occurred including one patient with laBCC on $200 \mathrm{mg}$ sonidegib who died of acute respiratory distress, one patient with laBCC on $800 \mathrm{mg}$ who died of cardiac arrest, one patient on $800 \mathrm{mg}$ with mBCC who died of sepsis, and one patient on $800 \mathrm{mg}$ with $\mathrm{mBCC}$ who died of respiratory arrest. The BOLT and ERIVANCE trials shared a similar incidence of adverse events of all grades. Additionally, the STEVIE trial, another multicenter study evaluating the safety of 499 total patients taking $150 \mathrm{mg}$ oral vismodegib once daily for the treatment of advanced BCC, reported a similar safety profile [29].

\section{Post-trial concerns \& present challenges}

The development of acquired resistance to HPIs has been demonstrated in nude mice implanted with medulloblastoma tumors derived from $\mathrm{Ptch}^{+/-} p 53^{-/-}$mice and poses a major concern [30]. While undergoing treatment with $20 \mathrm{mg} / \mathrm{kg} /$ day of sonidegib, the nude mice initially had decreased expression of Gli1 and near complete tumor repression. However, regrowth of tumors was seen on day 13 of the study. Amplification of Gli2, mutations in SMO or the upregulation of PI3K signaling has been suggested as possible mechanisms for the development of sonidegib resistance. The use of a PI3K/Tor inhibitor in addition to sonidegib has been suggested as a means to possibly overcome this resistance. A clinical trial investigating the use of a combination of sonidegib and buparlisib, a PI3K inhibitor, for the treatment of advanced BCC is currently underway [31].

Resistance to vismodegib in patients with BCC has been shown by molecular analysis of tumor biopsies to be consistently associated with hedgehog pathway reactivation [32]. This reactivation is mainly caused by $S M O$ 
mutations and less so by a gain-of-function mutation in Gli2 as well as a loss-of-function mutation in suppressor of fused, which negatively regulates the hedgehog pathway. In a case report of a 68-year-old woman who had complete regression of her laBCC after 16 weeks of vismodegib $150 \mathrm{mg}$ daily and subsequent development of recurrent tumors around the primary site after 20 weeks, different novel heterozygous missense SMO mutations were identified that were not found in pretreatment tumor tissue [33].

In a retrospective review of patients treated with vismodegib, $21 \%$ of the patients $(6 / 28)$ demonstrated tumor regrowth during treatment [34]. Similarly, treatment resistance with vismodegib was also observed in patients with nevoid basal cell carcinoma syndrome [35]. Danial et al. conducted an investigator-initiated open-label trial of sonidegib treatment for nine advanced basal cell carcinoma patients resistant to vismodegib [36]. The authors found that five patients experienced progressive disease with sonidegib and three patients experienced stable disease before stopping sonidegib, due to either an adverse event $(n=1)$ or the pursuit of surgical intervention $(n=2)$. The limitation of this study is the relatively short duration of treatment, as only one of nine patients received treatment beyond 14 weeks while some were treated for only 3 weeks. Therefore, the short duration of sonidegib exposure may not have been adequate to confer a measurable clinical response. Furthermore, the only patient who received treatment beyond 14 weeks (58 weeks) had an identifiable mutation on $\mathrm{D} 473 \mathrm{H}$ and later developed disease progression. Data performed with ${ }^{3} \mathrm{H}$-cyclopamine competition binding assays showing affinity (pKi) of vismodegib (GDC0449) and sonidegib (NVP-LDE225) for SMO both demonstrated a significant drop from 8.32 to 5.95 (>100-fold) and 7.68 to 6.91 , respectively, in the setting of SMO D473A mutations compared with wildtype [37]. However, if the mutation occurs at residue E518A, the affinity for vismodegib (GDC0449) decreases from 8.32 to 6.68 and increases slightly for sonidegib (NVP-LDE225). In other words, if a patient develops resistance to vismodegib due to a mutation at E518, he or she may still respond to treatment with sonidegib. Another smoothened antagonist, LY29040680, has been reported to be unaffected by a mutation at residue D473 with an affinity of 7.62 versus 7.51 in the wild-type despite the fact that LY29040680 and vismodegib share 14 contact residues [37]. Using the recently resolved crystal structure of the SMO transmembrane protein, the computational docking of vismodegib onto the SMO structure revealed that the mutations SMO-W281, SMO-V321, SMO-I408 and $S M O-C 469$ are located in close proximity to the drug-binding pocket [32,38]. These mutations affect the binding of vismodegib by disrupting the hydrophobic pocket, interfering with the positioning of adjacent binding residue, changing the conformation of the residues by packing the surrounding binding residues with delta methyl groups, and eliciting steric effects on the binding pockets, respectively [32]. Patients with acquired resistance to a specific HPI due to mutations in $S M O$ may or may not respond to a different HPI depending on the binding location, specific mutation/residue affected, and whether or not a conformational change is generated to prevent drug binding in a direct or indirect manner. The above findings in addition to patient's sequencing data may help predict a patient's treatment response to a HPI after failing treatment with another.

Another drawback of HPIs is the development of squamous cell carcinoma (SCC) due to an unclear mechanism. Although it may be argued that patients with BCCs are at a higher risk of developing another skin cancer, one study reported a 62-year-old patient with BCC on the back with metastasis to a left axillary lymph node who underwent 9 months of vismodegib therapy with an initial complete response in both her primary BCC lesion and lymph node metastasis [39]. Thirteen months later, the patient developed SCC in the left axillary node that shared the same PTCH1 and TP53 mutations as well as $90 \%$ of the genomic identity of the original BCC. In addition, this SCC also harbored NOTCH1/2 and KMT2C mutations, which are commonly seen in cutaneous SCC. The above phenomenon suggests that the patient's SCC may have evolved from a pre-existing BCC lesion through selective squamatization not suppressed by vismodegib. A single institution case-control study evaluating the risk of developing non-BCC malignancy after HPI exposure found a hazard ratio of 8.12 for the development of cutaneous squamous cell carcinoma in the vismodegib exposure group [40]. One shortcoming of the study was the variability of screening frequency for both the cases and controls. Patients in the vismodegib group typically were screened more frequently than the control group because they were either enrolled in clinical trials which required multiple study visits, or they were being monitored closely for vismodegib-associated side effects. A previous study has shown that cancer screening alone can lead to an increase in the incidence of nonmelanoma skin cancers [41]. In a recently published retrospective study, a total of 1675 patients who were treated with vismodegib as part of Phase I and Phase II clinical studies were compared with patients who received standard therapy for primary BCC. The authors concluded that vismodegib was not associated with an increased risk of subsequent SCC when compared with standard surgical treatment; rather, elevated cutaneous SCC risk in patients treated with vismodegib is likely due to more frequent screening [42]. 


\section{Management of hedgehog pathway inhibitor associated adverse events}

Another important area of study is the management of the adverse effects of HPIs such as muscle spasms, dysguesia and alopecia so that treatment duration can be prolonged and maximum benefit achieved. Lacouture et al. constructed an algorithm to manage the most frequently encountered HPI-related adverse effects [43]. To reduce the risk and severity of muscle spasms during HPI therapy, patient should be advised to keep hydrated and limit physical activity. Ally et al. saw a reduction in vismodegib-induced muscle cramps in their patients with the use of amlodipine, a calcium channel blocker, and recommend a 2-week trial of $10 \mathrm{mg}$ amlodipine for treatment; thus, it may be prudent to try amlodipine for sonidegib-induced muscle cramps [44]. Quinine at a dose of $200 \mathrm{mg}$ also demonstrated some benefit to reduce symptoms of muscle spasms [43]. The use of levocarnitine in alleviating muscle spasm due to HPIs had been investigated with results pending [45]. When adverse effects of sonidegib treatment become intolerable, treatment breaks can be helpful. Exploratory analysis from the STEVIE trial showed an increase in the median duration of treatment corresponding with an increase in the number of treatment breaks, with no impact on the overall efficacy of vismodegib [46]. Muscle spasms generally resolve 4-8 weeks after discontinuing the HPIs. Alopecia may take 6-12 months to resolve. Treatment options for alopecia include $2-5 \%$ minoxidil, which can be used in addition to concealment measures such as wearing a wig [43,47]. However, a longer duration of vismodegib treatment and an increased degree of treatment-related alopecia can lead to impaired and/or incomplete hair growth after completion of treatment [48]. For dysguesia, identification of food that is more pleasant for the patient as well as dietician referral can be helpful as it is only temporary and typically resolved 2-6 months after stopping vismodegib.

\section{Discussion}

The BOLT trial studied the use of sonidegib in a $200 \mathrm{mg}$ treatment arm and $800 \mathrm{mg}$ treatment arm for patients with laBCC not amenable to curative surgery or radiotherapy or patients with mBCC. Sonidegib has been shown to have clinical efficacy and a reasonable safety profile with the data from the $200 \mathrm{mg}$ treatment showing a more favorable benefit-to-risk profile in comparison to the $800 \mathrm{mg}$ treatment group. The 30 -month analysis has provided further confirmation of the clinical efficacy of the use of sonidegib for treatment of advanced BCC (Table 1).

Although there have not been a cross-trial comparison, sonidegib and vismodegib were compared using a matching-adjusted indirect comparison to reduce confounding of treatment effects which could have occurred in an unadjusted indirect comparison. Patients from the BOLT trial had an ORR of $56.7 \%$ and PFS of $56.7 \%$ and 22.1 months versus $47.6 \%$ and 9.5 months in the ERIVANCE trial, thus indicating a slightly greater benefit with sonidegib therapy [49].

Acquired resistance to HPIs limit their use for certain patient populations. To overcome this hurdle, induced blockade of Gli transcription factor downstream of SMO has been proposed. Future studies are needed to explore molecules that target Gli transcription factor and investigate their efficacy for decreasing HPI resistance during the treatment of BCC.

No large trials have been conducted on the use of sonidegib as a neoadjuvant agent. On the other hand, neoadjuvant use of vismodegib was investigated in an open-label, three-cohort, nonrandomized Phase II study to determine the rate and durability of complete histologic clearance $(\mathrm{CHC})$ of operable nodular $\mathrm{BCC}$ in patients who received different vismodegib regimens prior to MMS [50]. All three cohorts did not meet the primary efficacy end points, predefined as $\mathrm{CHC}>50 \%$ in cohorts 1 (received vismodegib for 12 weeks before MMS) and 3 (received vismodegib for 8 weeks on $/ 4$ weeks off/ 8 weeks on before MMS) and CHC $>30 \%$ in cohort 2 (received vismodegib for 12 weeks followed by 24 weeks of observation before MMS). Although other smaller studies have shown tumor size reduction with vismodegib therapy, convincing data from larger trials supporting the neoadjuvant use of HPIs is currently lacking [51-53].

\section{Conclusion}

HPIs have shown promise as a treatment option for patients with advanced BCC who are poor candidate for surgery or radiotherapy. The 30-month data from the BOLT trial reaffirmed the use of $200 \mathrm{mg}$ sonidegib due to its demonstrated safety and long-term efficacy. Future studies are needed to better understand acquired resistance and ways to overcome it. Combination therapies of HPIs with other agents are currently being investigated in various human tumors. Dosing regimen adjustment with potential treatment holiday as well as novel approaches for side profile management might provide options for improving the tolerability of this therapy. 


\section{Executive summary}

\section{Mechanism of action}

- Sonidegib binds to and inhibits SMO, a transmembrane protein involved in hedgehog pathway signal transduction and thus decreases the proliferation of malignant cells.

Pharmacokinetic properties

- Sonidegib's half-life is 29.6 days with around $6-7 \%$ of the drug being absorbed.

- The median time-to-peak concentration $\left(t_{\max }\right)$ is $2-4 \mathrm{~h}$.

- Steady state is reached at around 4 months after initial dosing.

- Sonidegib has an extensive volume of distribution of approximately $2500 \mathrm{~L}$.

- Sonidegib is chiefly metabolized by enzyme CYP3A and eliminated hepatically.

- Absorbed sonidegib is eliminated primarily through hydrolytic and oxidative metabolism. Close to $70 \%$ of absorbed agent is excreted in the feces and $30 \%$ in the urine.

- Unabsorbed sonidegib is eliminated in the feces.

Clinical efficacy (locally advanced basal cell carcinoma)

- In the 30-month BOLT trial analysis, an objective response rate (per central review) was achieved in 56.1 and $45.3 \%$ of patients in the 200 and $800 \mathrm{mg}$ sonidegib treatment arms, respectively.

- Clinical benefit defined as best percentage change from baseline in the size of target lesion was seen in 92.3 and $90.1 \%$ of patients treated with 200 and $800 \mathrm{mg}$ sonidegib, respectively.

- The median duration of response was 26.1 and 23.7 months for the 200 and $800 \mathrm{mg}$ groups, respectively.

Clinical efficacy (metastatic basal cell carcinoma)

- In the 30 -month BOLT trial analysis, 7.7 and $17.4 \%$ of patients achieved an ORR in the 200 and $800 \mathrm{mg}$ arms, respectively.

- Clinical benefit defined as best percentage change from baseline in the size of target lesion was observed in 91.7 and $84.2 \%$ of patients in the 200 and $800 \mathrm{mg}$ arms, respectively.

- The median duration of response was 24.0 months for the 200 group and not reached for the 800 mg group.

Safety \& tolerability

- Contraindications to sonidegib include pregnancy or breast-feeding as the drug may cause severe birth defects or death in a developing fetus.

- Common adverse events include muscle spasms, dysgeusia, fatigue, nausea and elevated blood creatine kinase as reported in the BOLT trial.

Drug interactions

- CYP3A inhibitor drug interactions have the potential to increase the risk of muscle toxicity.

Dosage \& administration

- It is recommended that a dose of $200 \mathrm{mg}$ of sonidegib (trade name, ODOMZO) be taken by mouth once a day on an empty stomach, no less than $1 \mathrm{~h}$ prior to or $2 \mathrm{~h}$ after a meal.

- Serum creatine kinase levels and kidney function tests must be obtained before starting sonidegib in all patients as detailed in the package insert.

Financial \& competing interests disclosure

MR Migden has participated on advisory boards and received honoraria from Genentech, Inc.; Novartis Pharmaceuticals Corporation; and Eli Lilly and Company. The authors have no other relevant affiliations or financial involvement with any organization or entity with a financial interest in or financial conflict with the subject matter or materials discussed in the manuscript apart from those disclosed.

No writing assistance was utilized in the production of this manuscript.

\section{References}

Papers of special note have been highlighted as: $\bullet$ of interest; $\bullet \bullet$ of considerable interest

1 Mohan SV, Chang ALS. Advanced basal cell carcinoma: epidemiology and therapeutic innovations. Curr. Dermatol. Rep. 3(1), 40-45 (2014).

2 Chren M-M, Linos E, Torres JS, Stuart SE, Parvataneni R, Boscardin WJ. Tumor recurrence 5 years after treatment of cutaneous basal cell carcinoma and squamous cell carcinoma. J. Invest. Dermatol. 133(5), 1188-1196 (2013).

3 Griffiths RW, Suvarna SK, Stone J. Do basal cell carcinomas recur after complete conventional surgical excision? Br. J. Plast. Surg. 58(6), 795-805 (2005). 
4 Hill VK, Gartner JJ, Samuels Y, Goldstein AM. The genetics of melanoma: recent advances. Annu. Rev. Genomics Hum. Genet. 14(1), 257-279 (2013).

5 Goldstein AM, Fraser MC, Struewing JP et al. Increased risk of pancreatic cancer in melanoma-prone kindreds with p16 INK4 mutations. N. Engl. J. Med. 333(15), 970-975 (1995).

6 Goldstein AM, Tucker MA. Genetic epidemiology of cutaneous melanoma: a global perspective. Arch. Dermatol. 137(11), 1493-1496 (2001).

7 Mosterd K, Krekels GA, Nieman FH et al. Surgical excision versus Mohs' micrographic surgery for primary and recurrent basal-cell carcinoma of the face: a prospective randomised controlled trial with 5-years' follow-up. Lancet Oncol. 9(12), 1149-1156 (2008).

8 Lo JS, Snow SN, Reizner GT, Mohs FE, Larson PO, Hruza GJ. Metastatic basal cell carcinoma: report of twelve cases with a review of the literature. J. Am. Acad. Dermatol. 24(5 Pt 1), 715-719 (1991).

9 Seo S-H, Shim W-H, Shin D-H, Kim Y-S, Sung H-W. Pulmonary metastasis of basal cell carcinoma. Ann. Dermatol. 23(2), 213-216 (2011).

10 Sekulic A, Mangold AR, Northfelt DW, LoRusso PM. Advanced basal cell carcinoma of the skin: targeting the hedgehog pathway. Curr. Opin. Oncol. 25(3), 218-223 (2013).

11 Epstein EH. Basal cell carcinomas: attack of the hedgehog. Nat. Rev. Cancer 8(10), 743-754 (2008).

12 Xie J, Murone M, Luoh SM et al. Activating smoothened mutations in sporadic basal-cell carcinoma. Nature 391(6662), 90-92 (1998).

13 Gailani MR, Ståhle-Bäckdahl M, Leffell DJ et al. The role of the human homologue of Drosophila patched in sporadic basal cell carcinomas. Nat. Genet. 14(1), 78-81 (1996).

14 Migden MR, Guminski A, Gutzmer R et al. Treatment with two different doses of sonidegib in patients with locally advanced or metastatic basal cell carcinoma (BOLT): a multicentre, randomised, double-blind Phase 2 trial. Lancet Oncol. 16(6), 716-728 (2015).

-. The original article for the Phase II BOLT trial.

15 Chen L, Silapunt S, Migden MR. Sonidegib for the treatment of advanced basal cell carcinoma: a comprehensive review of sonidegib and the BOLT trial with 12-month update. Future Oncol. 12(18), 2095-2105 (2016).

- A comprehensive review of sonidegib and the BOLT trial with a 12-month update.

16 Lear JT, Migden MR, Lewis KD et al. Long-term efficacy and safety of sonidegib in patients with locally advanced and metastatic basal cell carcinoma: 30-month analysis of the randomized Phase 2 BOLT study. J. Eur. Acad. Dermatology Venereol. doi:10.1111/jdv.14542 (2017) (Epub ahead of print).

17 Stone DM, Hynes M, Armanini M et al. The tumour-suppressor gene patched encodes a candidate receptor for sonic hedgehog. Nature 384(6605), 129-134 (1996).

18 Aszterbaum M, Rothman A, Johnson RL et al. Identification of mutations in the human PATCHED gene in sporadic basal cell carcinomas and in patients with the basal cell nevus syndrome. J. Invest. Dermatol. 110(6), 885-888 (1998).

19 Pan S, Wu X, Jiang J et al. Discovery of NVP-LDE225, a potent and selective smoothened antagonist. ACS Med. Chem. Lett. 1(3), 130-134 (2010).

20 Rodon J, Tawbi HA, Thomas AL et al. A Phase I, multicenter, open-label, first-in-human, dose-escalation study of the oral smoothened inhibitor sonidegib (LDE225) in patients with advanced solid tumors. Clin. Cancer Res. 20(7), 1900-1909 (2014).

21 Goel V, Hurh E, Stein A et al. Population pharmacokinetics of sonidegib (LDE225), an oral inhibitor of hedgehog pathway signaling, in healthy subjects and in patients with advanced solid tumors. Cancer Chemother. Pharmacol. 77(4), 745-755 (2016).

22 Zollinger M, Lozac'h F, Hurh E, Emotte C, Bauly H, Swart P. Absorption, distribution, metabolism, and excretion (ADME) of ${ }^{14}$ C-sonidegib (LDE225) in healthy volunteers. Cancer Chemother. Pharmacol. 74(1), 63-75 (2014).

23 Skvara H, Kalthoff F, Meingassner JG et al. Topical treatment of basal cell carcinomas in nevoid basal cell carcinoma syndrome with a smoothened inhibitor. J. Invest. Dermatol. 131(8), 1735-1744 (2011).

24 Clinical trials database: NCT01033019. https://clinicaltrials.gov/ct2/show/NCT01033019

25 Eisenhauer EA, Therasse P, Bogaerts J et al. New response evaluation criteria in solid tumours: revised RECIST guideline (version 1.1). Eur. J. Cancer 45(2), 228-247 (2009).

26 Dessinioti C, Plaka M, Stratigos AJ. Vismodegib for the treatment of basal cell carcinoma: results and implications of the ERIVANCE BCC trial. Future Oncol. 10(6), 927-936 (2014).

27 Kumari A, Ermilov AN, Allen BL, Bradley RM, Dlugosz AA, Mistretta CM. Hedgehog pathway blockade with the cancer drug LDE225 disrupts taste organs and taste sensation. J. Neurophysiol. 113(3), 1034-1040 (2015).

28 Dummer R, Guminski A, Gutzmer R et al. The 12-month analysis from Basal Cell Carcinoma Outcomes with LDE225 treatment (BOLT): a Phase II, randomized, double-blind study of sonidegib in patients with advanced basal cell carcinoma. J. Am. Acad. Dermatol. 75(1), 113.e5-125.e5 (2016).

-. The 12-month analysis from the BOLT study.

29 Basset-Seguin N, Hauschild A, Grob J-J et al. Vismodegib in patients with advanced basal cell carcinoma (STEVIE): a pre-planned interim analysis of an international, open-label trial. Lancet Oncol. 16(6), 729-736 (2015). 
Buonamici S, Williams J, Morrissey M et al. Interfering with resistance to smoothened antagonists by inhibition of the PI3K pathway in medulloblastoma. Sci. Transl. Med. 2(51), 51-70 (2010).

31 Clinical trials database: NCT02303041. https://clinicaltrials.gov/ct2/show/NCT02303041

32 Sharpe HJ, Pau G, Dijkgraaf GJ et al. Genomic analysis of smoothened inhibitor resistance in basal cell carcinoma. Cancer Cell 27(3), 327-341 (2015).

- Insightful article on hedgehog pathway inhibitor resistance with molecular analysis of basal cell carcinoma biopsy samples.

33 Brinkhuizen T, Reinders MG, van Geel M et al. Acquired resistance to the hedgehog pathway inhibitor vismodegib due to smoothened mutations in treatment of locally advanced basal cell carcinoma. J. Am. Acad. Dermatol. 71(5), 1005-1008 (2014).

34 Chang ALS, Oro AE. Initial assessment of tumor regrowth after vismodegib in advanced basal cell carcinoma. Arch. Dermatol. 148(11), $1324-1325$ (2012).

35 Wolfe CM, Green WH, Cognetta AB, Hatfield HK. Basal cell carcinoma rebound after cessation of vismodegib in a nevoid basal cell carcinoma syndrome patient. Dermatol. Surg. 38(11), 1863-1866 (2012).

36 Danial C, Sarin KY, Oro AE, Chang ALS. An investigator-initiated open-label trial of sonidegib in advanced basal cell carcinoma patients resistant to vismodegib. Clin. Cancer Res. 22(6), 1325-1329 (2016).

37 Wang C, Wu H, Evron T et al. Structural basis for smoothened receptor modulation and chemoresistance to anticancer drugs. Nat. Commun. 5, 4355 (2014)

38 Wang C, Wu H, Katritch V et al. Structure of the human smoothened receptor bound to an antitumour agent. Nature 497(7449), 338-343 (2013).

39 Ransohoff KJ, Tang JY, Sarin KY. Squamous change in basal-cell carcinoma with drug resistance. N. Engl. J. Med. 373(11), 1079-1082 (2015).

40 Mohan SV, Chang J, Li S, Henry AS, Wood DJ, Chang ALS. Increased risk of cutaneous squamous cell carcinoma after vismodegib therapy for basal cell carcinoma. JAMA Dermatol. 152(5), 527-532 (2016).

41 Eisemann N, Waldmann A, Geller AC et al. Non-melanoma skin cancer incidence and impact of skin cancer screening on incidence. J. Invest. Dermatol. 134(1), 43-50 (2014).

42 Bhutani T, Abrouk M, Sima CS et al. Risk of cutaneous squamous cell carcinoma after treatment of basal cell carcinoma with vismodegib. J. Am. Acad. Dermatol. 77(4), 713-718 (2017).

- Article regarding the risk of squamous cell carcinoma after treatment of basal cell carcinoma with vismodegib.

43 Lacouture ME, Dréno B, Ascierto PA et al. Characterization and management of hedgehog pathway inhibitor-related adverse events in patients with advanced basal cell carcinoma. Oncologist 21(10), 1218-1229 (2016).

44 Ally MS, Tang JY, Lindgren J et al. Effect of calcium channel blockade on vismodegib-induced muscle cramps. JAMA Dermatol. 151(10), 1132-1134 (2015).

45 Clinical trials database: NCT01893892. https://clinicaltrials.gov/ct2/show/NCT01893892

46 Dummer R, Basset-Seguin N, Hansson J et al. Impact of treatment breaks on vismodegib patient outcomes: exploratory analysis of the STEVIE study. J. Clin. Oncol. 33(15 Suppl.), 9024 (2015).

47 MacDonald JB, MacDonald B, Golitz LE, LoRusso P, Sekulic A. Cutaneous adverse effects of targeted therapies: part II: inhibitors of intracellular molecular signaling pathways. J. Am. Acad. Dermatol. 72(2), 221-236-238 (2015).

48 Tang JY, Ally MS, Chanana AM et al. Inhibition of the hedgehog pathway in patients with basal-cell nevus syndrome: final results from the multicentre, randomised, double-blind, placebo-controlled, Phase 2 trial. Lancet Oncol. 17(12), 1720-1731 (2016).

49 Odom D, Mladsi D, Purser M et al. A matching-adjusted indirect comparison of sonidegib and vismodegib in advanced basal cell carcinoma. J. Skin Cancer 2017, 6121760 (2017).

50 Sofen H, Gross KG, Goldberg LH et al. A Phase II, multicenter, open-label, 3-cohort trial evaluating the efficacy and safety of vismodegib in operable basal cell carcinoma. J. Am. Acad. Dermatol. 73(1), 99.e1-105.e1 (2015).

51 Alcalay J, Tauber G, Fenig E, Hodak E. Vismodegib as a neoadjuvant treatment to Mohs surgery for aggressive basal cell carcinoma. J. Drugs Dermatol. 14(3), 219-223 (2015).

52 Chang ALS, Atwood SX, Tartar DM, Oro AE. Surgical excision after neoadjuvant therapy with vismodegib for a locally advanced basal cell carcinoma and resistant basal carcinomas in Gorlin syndrome. JAMA Dermatol. 149(5), 639-641 (2013).

53 Kahana A, Worden FP, Elner VM. Vismodegib as eye-sparing adjuvant treatment for orbital basal cell carcinoma. JAMA Ophthalmol. 131(10), 1364-1366 (2013). 
